\title{
NR 17 NO CONTEXTO ACADÊMICO: APLICADA NA EDUCAÇÃO TÉCNICA
}

\section{NR 17 IN THE ACADEMIC CONTEXT: APPLIED IN TECHNICAL EDUCATION}

\author{
Rômulo Maziero $^{1 *}$, \& Frederico da Silva Fortunato ${ }^{2}$ \\ 12 Instituto Federal de Educação, Ciência e Tecnologia do Espírito Santo - IFES. \\ 1*maziero.ifes@gmail.com² ffortunato@ifes.edu.br
}

\section{ARTIGO INFO.}

\section{Recebido em: 24.12.2020}

Aprovado em: 27.01.2021

Disponibilizado em: 05.02.2021

Palavras-Chave:

ergonomia; educação profissional; ensino técnico.

\section{KEYWORDS:}

ergonomics; professional education; technical education.

*Autor Correspondente: Maziero, R.

\section{RESUMO}

A natureza interdisciplinar da ergonomia a torna notavelmente aplicável a vários campos que envolvem desempenho humano. A educação é um campo em que a ergonomia pode dar uma contribuição significativa, mas a aplicação da ergonomia educacional recebe apenas uma atenção limitada. Deste modo, o objetivo do presente estudo foi analisar os riscos ergonômicos, de servidores estaduais (professores, administrativo) e terceirizados (auxiliar de serviços gerais, vigilantes) de uma instituição de educação profissional técnica de nível médio, de forma a contribuir com a organização e/ou reorganização ergonômica no ambiente educacional. Foram conduzidos questionários eletrônicos semiestruturados quantitativos em forma de entrevistas individuais, para os grupos servidores e terceirizados. Posteriormente, a intervenção no ambiente educacional envolveu um curso com a temática ergonomia educacional, aplicado ao grupo alunos, além de uma campanha educativa - Webinar. Os resultados evidenciaram, de forma geral, os níveis de desconforto/dor classificados em moderado e intenso, com base nos questionários respondidos pelos servidores e terceirizados. Notou-se ainda o desconhecimento dos alunos em relação à ergonomia educacional e áreas afins. Conclui-se que é necessária intervenção educacional, ergonômica e interação professor-aluno-ambiente na temática ergonomia.

\begin{abstract}
The interdisciplinary nature of ergonomics makes it remarkably applicable to various fields that involve human performance. Education is a field in which ergonomics can make a significant contribution, but the application of educational ergonomics receives only limited attention. Thus, the objective of the present study was to analyze the ergonomic risks, of state employees (teachers, administrative) and outsourced workers (general services assistant, security guards) of a medium level technical professional education institution, in order to contribute to the organization and/or ergonomic reorganization in the educational environment. Quantitative semi-structured electronic questionnaires were conducted in the form of individual interviews, for server and outsourced groups. Subsequently, the intervention in the educational environment involved a course on educational ergonomics, applied to the group of students, in addition to an educational campaign Webinar. The results showed, in general, the levels of discomfort/pain classified as moderate and intense, based on the questionnaires answered by the servers and outsourced workers. It was also noted the students' lack of knowledge regarding educational ergonomics and related areas. In conclusion it is necessary that educational and ergonomic intervention and greater teacher-student-educational environment interaction in the universe of ergonomics.
\end{abstract}




\section{INTRODUÇÃO}

As duas décadas iniciais do século XXI têm intensificado a percepção dos profissionais da educação, que o processo de reestruturação produtivo e acelerado da educação, tem deixado esses profissionais a sensação de estar trabalhando no limite de suas capacidades físicas e emocionais.

No Brasil, as principais causas de absenteísmo e afastamento do docente da sala de aula têm sido os transtornos mentais e comportamentais, por exemplo síndrome de Burnout, problemas cardiológicos e circulatórios; os distúrbios da fala e da voz e os transtornos osteomusculares, ortopédicos e músculos esqueléticos (Silva-Macaia et al., 2016).

Desta forma, existe urgência no repensar sobre as condições de trabalho que os profissionais da educação estão submetidos. Esse repensar passa por uma intervenção estratégica na abordagem da ergonomia. Para a Associação Brasileira de Ergonomia (ABERGO, 2020), a ergonomia é uma disciplina científica relacionada ao entendimento das interações entre seres humanos e outros elementos ou sistemas, e à aplicação de teorias, princípios, dados e métodos a projetos a fim de otimizar o bem-estar humano e o desempenho global do sistema.

Atualmente, na educação profissional técnica de nível médio, a ergonomia é restrita como unidade curricular ou conteúdo programático de distintos componentes curriculares. Entretanto, segundo Alves (2018), em ergonomia a atividade compreende a presença de atores sociais (profissionais da educação) na mediação do prescrito ao real, aquilo que o trabalhador faz, engaja e mobiliza (inteligência, interfaces com o coletivo, corpo, memória, entre outros) no processo de realização da tarefa.

Os atores sociais de instituições de ensino exercem ação mútua no contexto acadêmico, em abordagens físicas, cognitivas e organizacionais. Segundo Ansari, Nikpay e Varmazyar (2018), o ambiente físico das instalações educacionais pode ajudar no ensino, na aprendizagem e no desempenho acadêmico, enquanto instalações inadequadas podem causar estresse e comportamentos agitados nos alunos. Assim como, professores e outros colaboradores educacionais convivem com o risco de esgotamento físico (fadiga, lesões por esforços repetitivos, distúrbios osteomusculares relacionados ao trabalho, inflamações na coluna, entre outros) e mental (emocional, ansiedade, depressão, entre outros), considerando as dificuldades das condições de trabalho no exercício da atividade, como, por exemplo, tempo excessivo em pé, ou sentado em cadeiras não projetadas interferindo na postura e no uso da voz, reduzidos salários, jornada de trabalho exaustiva, excesso de alunos, indisciplinas, entre outros (Rantala, Sala, Kankare, 2018; Safarian, Rahmati-Najarkolaei, Mortezapour, 2018).

Ademais, segundo Leme e Maia (2015), o profissional da educação também está exposto a condições de trabalho inexistentes, como o uso de novas tecnologias em sala de aula (projetor, quadro interativo, computadores, sistemas modernos de áudio, entre outros). Por um lado, o benefício de uma classe mais dinâmica e interessante; por outro, o risco de má postura no manuseio desses dispositivos, desencadeando dor nos músculos do pescoço e ombro, dor nas pernas e pés, além de dor de cabeça, fadiga visual e auditiva. Deste modo, a 


$$
\text { - } 3 \text { - }
$$

Citação (APA): Maziero, R., \& Fortunato, F. da S. (2021). NR 17 no contexto acadêmico: aplicada na educação técnica. Brazilian Journal of Production Engineering, 7(1), 1-16.

melhoria das condições de trabalho é, prioritariamente, um processo de transformação social, cabendo ao conhecimento científico determinar os fundamentos desta transformação por meio, por exemplo, da ergonomia de aprendizagem e instrucional. O estudo do trabalho e a aplicação prática de seus resultados permitem a consolidação desse projeto de transformação.

Neste contexto, surge o seguinte questionamento: Existe desconhecimento de práticas ergonômicas por parte dos atores que atuam no ambiente educacional? É provável que a resposta seja positiva, ou seja, os atores no ambiente escolar desconhecem sobre as práticas ergonômicas. Destarte, a escolha do tema justifica-se devido à preocupação crescente com o adoecimento dos profissionais da educação, especialmente nas instituições públicas, onde é possível perceber a carência de estudos que aborda as práticas ergonômicas (ergonomia educacional) incluindo todos os atores do ambiente acadêmico, bem como, de políticas que contribuam de fato para a saúde desses colaboradores e conscientização dos alunos quanto às práticas ergonômicas e programas de ergonomia.

O objetivo da pesquisa foi analisar os riscos ergonômicos, de servidores estaduais e terceirizados de uma instituição de ensino técnico, e o grau de percepção e participação dos atores (servidores, alunos e terceirizados) com a temática ergonomia.

\section{FUNDAMENTAÇÃO TEÓRICA}

A ergonomia educacional é o ramo da ergonomia relacionada à interação entre desempenho e design educacional. Em um sistema escolar identifica-se cinco componentes para ergonomia educacional: ergonomia de aprendizagem; ergonomia instrucional; ergonomia de instalações educacionais; ergonomia de equipamento educacional; e ergonomia de ambiente educacional. Esse sistema contém muitos elementos distintos, variando de natureza micro a macro ergonômica, como equipamentos escolares, trabalho, espaços, instalações/ambientes da escola e organização da escola (Gligorović, Desnica, Palinkaš, 2018).

Muitos trabalhos publicados na literatura sobre ergonomia educacional, fatores humanos/problemas osteomusculares e condições de trabalho (materiais e psicológicos) tratam da ergonomia de instalações educacionais (salas de aula, bibliotecas, laboratórios, corredores, iluminação, fatores físicos como aquecimento, refrigeração, ruído, arranjo físico, entre outros), de equipamento educacional (mesas, cadeiras, computadores, mochilas, entre outros), e de organização/ambiente educacional (disciplinas, currículo, duração e horário dos estudos, intervalos para descanso, atividades físicas, estruturas departamentais, governança, regras da escola, segurança pessoal, prioridades educacionais, internacionalização, globalização, entre outros), aplicada ao ensino fundamental, médio e superior de instituições públicas e privadas, direcionada a alunos e professores (Oyewole, Haight, Freivalds, 2010; Cañete et al., 2015; Ansari, Nikpay, Varmazyar, 2018; Fidelis et al., 2018; Gligorović, Desnica, Palinkaš, 2018; Parvez, Rahman, Tasnim, 2019; Sarmento, Villarouco, Attaianese, 2019).

Todavia, pesquisas em instituições públicas de ensino técnico envolvendo todos os profissionais da educação e alunos na ergonomia educacional, especialmente na ergonomia de aprendizagem (métodos de aprendizagem/ensino, pedagogia, entre outros) e instrucional 
(escola, direitos humanos, políticas nacionais, entre outros) continuam fracas, conforme Gligorović, Desnica e Palinkaš (2018) e Sarmento, Villarouco e Attaianese (2019).

Poucos trabalhos versam sobre a ergonomia de aprendizagem e instrucional, como no estudo de Okulova (2020), sobre a abordagem ergonômica do ensino superior de estudantes de psicologia e pedagogia. A autora identificou a necessidade do desenvolvimento da cultura ergonômica dos professores e destacou os componentes da abordagem ergonômica como sendo, conhecimento ergonômico, habilidades, pensamento e orientação.

Assim como, na pesquisa realizada por Safarian, Rahmati-Najarkolaei e Mortezapour (2018), com 240 colaboradores da Universidade de Ciências Médicas de Teerã (TUMS, Irã), com experiência de trabalho superior a um ano, com mais de três horas de trabalho com computadores por dia. Os resultados mostraram a eficácia de intervenções educacionais e ergonômicas na redução dos fatores de riscos ergonômicos (repetitividade, ritmo excessivo de trabalho, postura inadequada, monotonia, entre outros) e a prevalência de desconfortos entre os usuários de computador. No entanto, foi revelado que o uso de intervenções organizacionais, como enriquecimento no trabalho, aprimoramento e rotação, por si só, não é um método eficaz para reduzir os fatores de risco de ergonomia e a prevalência de desconfortos. O uso simultâneo de métodos complexos, como intervenções ergonômicas, educacionais (ergonomia educacional) e organizacionais, entre trabalhadores de escritório, pode produzir resultados desejáveis na redução de fatores de risco para distúrbios osteomusculares.

\section{Metodologia}

\section{Tipo de Pesquisa}

Pesquisa bibliográfica como base metodológica. Este tipo de pesquisa utiliza-se de registros, objetos ou fenômenos efetivos discutidos por outros pesquisadores, que direcionam novos trabalhos. Caracteriza-se este trabalho como um estudo de caso quantitativo-descritivo, pois trata-se de um assunto específico sobre abordagem do problema dentro de um método de pesquisa ampliada, fornecendo dados estatísticos de uma determinada população (amostragem representativa) e suas características em situação real, descrevendo-as.

\section{Local da pesquisa e amostragem da população}

A pesquisa foi realizada no Centro Estadual de Educação Técnica (CEET) Talmo Luiz Silva, em João Neiva, Espírito Santo (Brasil). Instituição de educação profissional técnica, criada e mantida pelo Governo do Estado do Espírito Santo (Resolução CEE/ES - n. 221-R, de 27/10/2006, DO de 30/10/2006, inauguração em 19/12/2006), e como órgão gestor a Secretaria de Estado da Ciência, Tecnologia, Inovação e Educação Profissional (SECTI). O CEET Talmo Luiz Silva oferece cursos nos eixos tecnológicos de controle e processos industriais, segurança, gestão e negócios. Atualmente, a instituição disponibiliza cursos Técnicos em Administração, Automação Industrial, Mecânica e Segurança do Trabalho.

Para cálculo amostral da população utilizou-se a equação $\frac{\frac{z^{2} \cdot p(1-p)}{e^{2}}}{1+\left(\frac{z^{2} \cdot p(1-p)}{e^{2} N}\right)}$. Onde, $z$ é o grau de confiança em desvios padrões; $e$ a margem de erro; $N$ o tamanho da população e $p=0,5$. 
A população é composta por servidores, alunos (maioridade plena, Código Civil Lei $\mathrm{n}^{\circ}$ 10.406, de 10 de janeiro de 2002) e terceirizados. Na Tabela 1 estão listados os grupos de atores envolvidos no estudo, respectivos quantitativos e margem de erro. A população analisada corresponde ao primeiro semestre de 2020.

Tabela 1. Atores da pesquisa.

\begin{tabular}{|c|c|c|c|c|}
\hline Grupos & \multicolumn{2}{|l|}{ Categorias } & Quantitativos & $e=5 \%$ \\
\hline \multirow{2}{*}{ Servidores } & ${ }^{1}$ Professores & & 37 & 34 \\
\hline & ${ }^{2}$ Administrativo & & 6 & 6 \\
\hline \multirow{12}{*}{ Alunos } & \multirow{3}{*}{ Administração } & Matutino & 13 & \multirow{3}{*}{68} \\
\hline & & Vespertino & 41 & \\
\hline & & Noturno & 29 & \\
\hline & \multirow{3}{*}{ Automação Industrial } & Matutino & 17 & \multirow{3}{*}{89} \\
\hline & & Vespertino & 43 & \\
\hline & & Noturno & 56 & \\
\hline & \multirow{3}{*}{ Mecânica } & Matutino & 50 & \multirow{3}{*}{95} \\
\hline & & Vespertino & 14 & \\
\hline & & Noturno & 63 & \\
\hline & \multirow{3}{*}{ Segurança do Trabalho } & Matutino & 27 & \multirow{3}{*}{81} \\
\hline & & Vespertino & 34 & \\
\hline & & Noturno & 41 & \\
\hline \multirow{2}{*}{ Terceirizados } & \multirow{2}{*}{\multicolumn{2}{|c|}{$\begin{array}{l}\text { Auxiliar de Serviços Gerais (ASG) } \\
\text { Vigilantes }\end{array}$}} & 8 & 8 \\
\hline & & & 6 & 6 \\
\hline
\end{tabular}

Nota: ${ }^{1}$ Professor de Educação Profissional e Tecnológica - DT, Professor B - Efetivo, Professor P - Efetivo.

${ }^{2}$ Auxiliar Administrativo - DT, Secretário Educacional - DT, Auxiliar de Biblioteca - DT.

\section{Instrumentos e procedimentos de coleta e análise de dados}

Inicialmente, o projeto em conformidade com a Resolução 510/2016 foi submetido aos protocolos de pesquisa do Sistema CEP/CONEP - Comitê de Ética em Pesquisa/Conselho Nacional de Saúde - por meio da Plataforma Brasil, com a respectiva carta de anuência entre o pesquisador e a instituição autorizando a realização da pesquisa, em consonância com os objetivos, justificativa e metodologia antecipadamente apresentados no Termo de Consentimento de Livre Escolha (TCLE). O projeto foi aprovado sob o número do parecer 4.221.760 e Certificado de Apresentação de Apreciação Ética (CAAE) 34193620.6.0000.5072.

Na primeira etapa da pesquisa, foram aplicados questionários eletrônicos (uso da plataforma Google Forms) semiestruturados quantitativos em forma de entrevistas individuais, com 26 perguntas estruturadas (algumas perguntas permitiam a marcação de mais de uma opção) e fechadas, para os grupos servidores e terceirizados conforme registrado no TCLE. A estatística descritiva foi utilizada a fim de mapear o perfil do público-alvo, coletando informações com relação aos aspectos idade, sexo, estado civil, escolaridade, experiência na função, consequências maléficas extenuantes decorrentes do trabalho, treinamento de ergonomia, entre outros. O método de avaliação de dores (psicofísica) ocasionadas por problemas de postura utilizado foi o Diagrama de Dores (Figura 1), proposto por Corlett e Manenica (1980) apud Leme e Maia (2015), que busca verificar subjetivamente regiões do corpo divididas em 24 partes (lado direito e esquerdo), onde ocorrem maiores incidências de dores ou desconfortos ao término da jornada de trabalho.

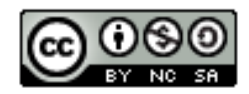


Figura 1. Mapa de segmentos corporais para avaliação biomecânica.
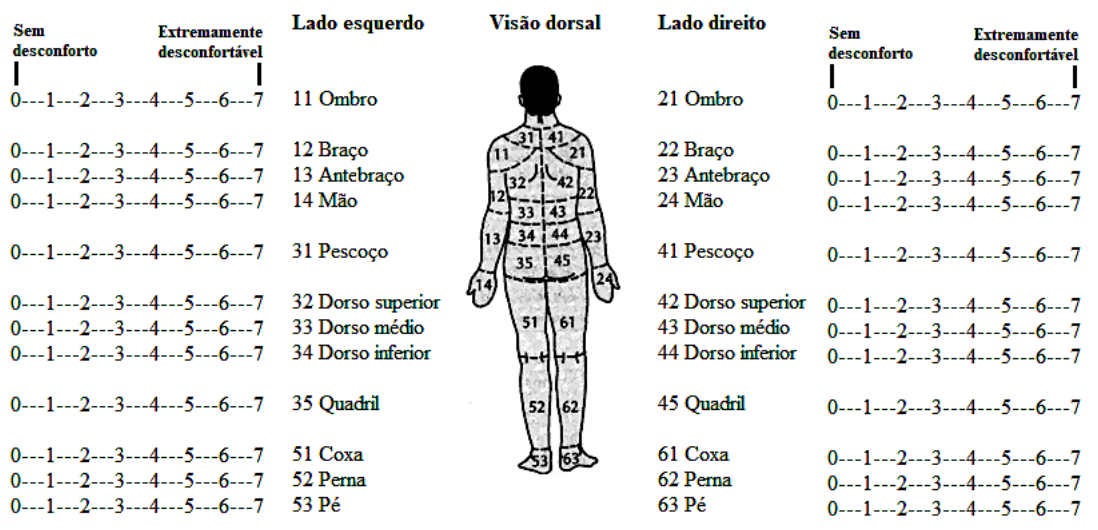

Fonte: Adaptado de Corlett e Manenica (1980) apud Leme e Maia (2015).

$\mathrm{Na}$ segunda etapa, a intervenção no ambiente educacional envolveu um curso on-line autoinstrucional sobre ergonomia educacional, com o tema "NR 17: O QUE É E PARA QUE SERVE?" (carga horária de 20 horas), além de uma campanha educativa - Webinar instrucional intitulada "AÇÃO ERGONÔMICA" (carga horária de 2 horas), ambos por meio da Plataforma Zoom e aplicado ao grupo alunos (eventos gratuitos, seleção de alunos de maioridade plena, participação dos cursos Técnicos em Administração, Automação Industrial, Mecânica e Segurança do Trabalho, de todos os turnos respectivamente). Essas iniciativas visam à construção de um ambiente humanizado (físico, cognitivo e organizacional). Foi realizada a coleta de informações a respeito dessas intervenções conforme TCLE, por meio de registros fotográficos via Web e formulários personalizados semiestruturados quantitativos em forma de entrevistas individuais, com 10 perguntas estruturadas e fechadas (on-line, plataforma Google Forms) quanto aos aspectos idade, sexo, curso, compreensão sobre proteção aos direitos dos trabalhadores (legislação), prática do processo de aprendizagem, formação em ergonomia, entre outros. Os formulários foram encaminhados aos alunos no término do curso e Webinar, com intuito de verificar o processo de visão ampla e participação dos alunos com a temática NR 17 (Ergonomia) em suas atividades desenvolvidas na instituição de ensino.

\section{RESULTADOS E DISCUSSÃO}

O tamanho da amostra foi atendido para margem de erro admissível de 5\%. Sendo 36 participantes para a categoria professores, 6 para administrativo, 8 para auxiliar de serviços gerais (ASG) e 6 para vigilantes.

\section{Fatores humanos e condições de trabalho - grupo servidores e terceirizados}

A categoria professores é composta de 47,2\% masculino e 52,7\% feminino, na faixa de 26 a 33 anos de idade $(30,5 \%)$ e 34 a 41 anos $(38,8 \%)$, com 63,8\% apresentando especialização completa. A faixa de idade de 33 a 40 anos é a fase em que a carreira profissional está sendo consolidada e entre 41 a 50 anos segundo Alves, Araújo e Aguiar (2014) a carreira já está consolidada, entretanto é nesse período em que a saúde se torna prioridade. Possuem experiência na instituição de até 1 ano $(22,2 \%)$ e acima de 10 anos $(36,1 \%)$, com jornada de trabalho de até 30 horas semanais $(30,5 \%)$ e acima de 40 horas semanais $(33,3 \%)$. Dos

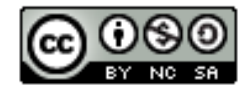


professores participantes, $47,2 \%$ realizam horas extras ao seu horário normal de trabalho, sendo $38,8 \%$ com até 10 horas semanais, fator este que pode contribuir para o desencadeamento de sintomas estressantes para a atividade (ALVES; ARAÚJO; AGUIAR, 2014). Quanto a condição salarial, 27,7\% recebem até 2 salários mínimos e 19,4\% até 4 salários mínimos.

Dos respondentes $36,1 \%$ relataram ter apresentado ou possuir algum tipo de distúrbio, dor ou doença ocupacional, como insônia (15\%), lombalgia e/ou outras dores (pés, mãos, ombros, entre outros) (25\%), cardiovasculares (por exemplo, hipertensão arterial) (15\%) e distúrbio da fala e da voz (20\%). Em estudo sobre posturas de trabalho dos professores e seus efeitos na voz, Rantala, Sala e Kankare (2018) mostraram que as posturas não ergonômicas dos professores durante o ensino foram associadas à produção de voz, embora as posturas de ensino não sejam tão estáticas quanto as posturas em certas outras ocupações, níveis baixos de contração muscular prolongada podem predispor a distúrbios, como demonstrado na medicina reabilitadora. Quando perguntados sobre o tempo de sono, 38,8\% disseram dormir, em média, até 6 horas, enquanto 50,0\% até 8 horas. Quanto a realização de avaliações preventivas, $88,8 \%$ confirmaram que sim, sendo $46,8 \%$ para exames periódicos (urina, fezes, sangue), 29,6\% para exames ginecológicos e 15,6\% para exames da mama. Com relação ao consumo de água durante a atividade laboral, 30,5\% disseram consumir até 4 copos e 33,3\% acima de 6 copos de água. 86,1\% dos professores participantes da pesquisa consomem café durante a atividade laboral, sendo $25,8 \%$ até 2 xícaras e acima de 3 xícaras, respectivamente. Ademais, 34,5\% faz uso de bebida alcoólica uma vez na semana e 3,6\% faz uso de cigarro.

Questionados sob a questão de treinamentos em ergonomia no trabalho, 83,3\% disseram que não receberam. Sobre os riscos na atividade no local de trabalho, 47,2\% relataram ruído excessivo, 33,3\% máquinas perigosas e desprotegidas e 36,1\% arranjo físico inadequado. 55,5\% faz uso do Equipamento de Proteção Individual (EPI), sendo 65,0\% jaleco, 38,8\% óculos de proteção e 41,6\% calçado de segurança. Quanto ao arranjo físico inadequado, o mesmo foi observado em pesquisa realizada por Sarmento, Villarouco e Attaianese (2019), em escolas de ensino médio e técnico, demonstrando inadequações ergonômicas nos ambientes de aprendizagem. Dos entrevistados 38,8\% relataram que não receberam instrução sobre o uso do EPI e 28,0\% afirmaram que às vezes sentem desconforto no uso do mesmo e 36,0\% nunca. Foi questionado sobre ter sofrido algum tipo de acidente durante o trabalho na instituição, 8,3\% disseram que sim, sendo 66,6\% não utilizavam o EPI durante o acidente. Ainda relataram que 33,3\% dos acidentes foram decorrentes de cortes e 66,6\% queimaduras. $75,0 \%$ dos entrevistados confirmaram ter passado por alguma situação de constrangimento na instituição de ensino técnico, sendo $44,4 \%$ para violência psicológica e $22,2 \%$ para violência moral.

Já os servidores administrativos são compostos por 16,6\% masculino e 83,3\% feminino, $33,3 \%$ na faixa de 34 a 41 anos de idade e 42 a 49 anos respectivamente, com 50,0\% apresentando ensino superior completo e $16,6 \%$ especialização completa. 33,3\% possuem experiência na instituição de até 1 ano e acima de 10 anos respectivamente, com jornada de trabalho de até 40 horas semanais $(100,0 \%)$. Desta categoria, todos disseram não realizar 
horas extras a sua jornada normal de trabalho. Quanto a salário, todos recebem até 2 salários mínimos.

Perguntados sobre ter apresentado ou possuir algum tipo de distúrbio, dor ou doença ocupacional, 66,6\% dos respondentes relataram que sim, como insônia (50\%) e outros (50\%). Quando interrogados sobre o tempo de sono, 33,3\% disseram dormir, em média, até 6 horas, enquanto 50,0\% até 8 horas. Quanto a realização de avaliações preventivas, 27,7\% confirmaram que sim, sendo $9,5 \%$ para exames periódicos (urina, fezes, sangue), 9,5\% para exames ginecológicos e 7,1\% para exames da mama. Verificando que $83,3 \%$ do público participante é feminino, o percentual para exames ginecológicos e da mama é consideravelmente baixo. Com relação ao consumo de água durante a atividade laboral, $16,6 \%$ disseram ingerir até 2 copos de água, 50,0\% até 4 copos e 33,3\% acima de 6 copos. Todos os servidores administrativos participantes consomem café durante a atividade laboral, sendo 66,6\% até 2 xícaras e 16,6\% acima de 3 xícaras. Ademais, 16,6\% faz uso de bebida alcoólica uma vez na semana e $83,3 \%$ não faz uso de cigarro.

Questionados sob a questão de treinamentos em ergonomia no trabalho, todos afirmaram que não receberam. Sobre os riscos na atividade no local de trabalho, 16,6\% relataram choque elétrico, $16,6 \%$ incêndio, $16,6 \%$ arranjo físico inadequado e $66,6 \%$ outros. Todos os servidores administrativos disseram não fazer uso do EPI. Foi questionado sobre ter sofrido algum tipo de acidente durante o trabalho na instituição, 100,0\% relataram que não. 50,0\% dos entrevistados afirmaram ter passado por alguma situação de constrangimento na instituição, sendo 33,3\% para violência psicológica e 66,6\% outros.

Para a categoria auxiliar de serviços gerais a mesma é composta de 20,0\% masculino e $80,0 \%$ feminino, na faixa de 42 a 49 anos de idade (40,0\%) e 50 anos ou mais $(60,0 \%)$, com $60,0 \%$ apresentando ensino fundamental completo e $20,0 \%$ ensino médio completo. Possuem experiência na instituição acima de 10 anos (40,0\%) e jornada de trabalho de até 40 horas semanais $(80,0 \%)$. Desta categoria, 20,0\% realizam horas extras de até 20 horas semanais ao seu horário normal de trabalho. Quanto a salário, 100,0\% recebem até 1 salário mínimo.

Perguntados sobre ter apresentado ou possuir algum tipo de distúrbio, dor ou doença ocupacional, $20,0 \%$ dos respondentes relataram que sim, como cardiovasculares $(66,6 \%)$ e outros $(33,3 \%)$. Quando questionados sobre o tempo de sono, 60,0\% disseram dormir, em média, até 6 horas, enquanto 40,0\% até 8 horas. Quanto a realização de avaliações preventivas, $100,0 \%$ confirmaram que sim, sendo $28,5 \%$ para exames periódicos, $21,4 \%$ para exames ginecológicos e $35,7 \%$ para exames da mama. Com relação ao consumo de água durante a atividade laboral, 40,0\% disseram ingerir até 4 copos de água e 20,0\% acima de 6 copos. Todos os ASG participantes consomem café durante a atividade laboral, sendo $60,0 \%$ até 2 xícaras e 40,0\% acima de 3 xícaras. Além disso, 11,1\% faz uso de cigarro e $33,3 \%$ o uso de bebida alcoólica uma vez na semana.

Questionados sob a questão de treinamentos em ergonomia no trabalho, 60,0\% disseram que não receberam. Sobre os riscos na atividade no local de trabalho, 60,0\% relataram queda de nível diferente, $20,0 \%$ choque elétrico e $20,0 \%$ calor excessivo. $100,0 \%$ deste público faz

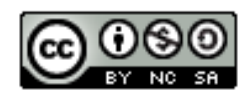

Esta obra está licenciada com uma Licença Creative Commons Atribuição-Não Comercial-Compartilha Igual 4.0 Internacional. Brazilian Journal of Production Engineering, São Mateus, Editora UFES/CEUNES/DETEC. 
uso do EPI, sendo 60,0\% calça de segurança, 80,0\% calçado de segurança e 60,0\% luvas de segurança. 40,0\% citaram que não receberam instrução sobre o uso do mesmo. 20,0\% disseram que sempre sentem desconforto no uso deste, $20,0 \%$ às vezes e $60,0 \%$ nunca. Foi questionado sobre ter sofrido algum tipo de acidente durante o trabalho na instituição, 40,0\% disseram que sim, sendo 100,0\% utilizavam o EPI durante o acidente. Ainda relataram que $50,0 \%$ dos acidentes foram decorrentes de corpo estranho projetado aos olhos e 50,0\% outros. $60,0 \%$ dos entrevistados afirmaram ter passado por alguma situação de constrangimento na instituição, sendo 66,6\% para violência psicológica e 33,3\% outros. A violência psicológica se caracteriza como uma "agressão emocional". Muitas vezes tão ou mais prejudicial que a violência física, caracteriza-se por ameaças, rejeição, depreciação, discriminação, humilhação, desrespeito ou mesmo punições exageradas. Mesmo não sendo formas físicas de agressão, "deixam marcas” difíceis de serem apagadas (Guimarães, 2009).

Na classe dos vigilantes tem-se 83,3\% masculino e 16,6\% feminino, 33,3\% na faixa de 26 a 33 anos de idade e 50 anos ou mais respectivamente, com $66,6 \%$ apresentando ensino médio completo e $16,6 \%$ ensino superior completo. Possuem experiência na instituição de até 5 anos $(33,3 \%)$ e até 6 anos $(16,6 \%)$, com jornada de trabalho de até 40 horas semanais $(50,0 \%)$ e acima de 40 horas semanais (33,3\%). Desta categoria, todos disseram não realizar horas extras ao seu horário normal de expediente. Quanto a salário, 100,0\% recebem até 2 salários mínimos.

Alguns respondentes afirmaram ter apresentado ou possuir algum tipo de distúrbio, dor ou doença ocupacional, como lombalgia e/ou outras dores (16,6\%). Quando perguntados sobre o tempo de sono, 50,0\% disseram dormir, em média, até 6 horas, enquanto 33,3\% até 8 horas. Quanto a realização de avaliações preventivas, 66,6\% confirmaram que sim, sendo $80,0 \%$ para exames periódicos (urina, fezes, sangue) e 20,0\% para exames ginecológicos. Para exames de próstata não houveram respostas, considerando que 33,3\% da classe possuem 50 anos ou mais. Com relação ao consumo de água durante a atividade laboral, $33,3 \%$ disseram ingerir até 2 copos de água, 16,6\% até 4 copos e 33,3\% acima de 6 copos. $66,6 \%$ dos vigilantes consomem café durante a atividade laboral, sendo 50,0\% até 3 xícaras e 25,0\% acima de 3 xícaras. Além do mais, 20,0\% faz uso de cigarro e bebida alcoólica uma vez na semana, respectivamente.

Questionados sob a questão de treinamentos em ergonomia no trabalho, 50,0\% disseram que não receberam. Sobre os riscos na atividade no local de trabalho, 16,6\% relataram queda de nível diferente, $33,3 \%$ incêndio e 50,0\% outros. 66,6\% dos vigilantes faz uso do EPI, sendo $25,0 \%$ calçado de segurança e 75,0\% outros (ex. colete balístico). 20,0\% mencionaram que não receberam instrução sobre o uso do EPI e 16,6\% disseram que raramente sentem desconforto no uso deste e $66,6 \%$ nunca. Foi questionado sobre ter sofrido algum tipo de acidente durante o trabalho na instituição, todos disseram que não. 16,6\% dos entrevistados afirmaram ter passado por alguma situação de constrangimento na instituição, sendo $16,6 \%$ para indisciplina. 


\section{Diagrama de Dores - grupo servidores e terceirizados}

Nas Tabelas 2-6 são apresentados os segmentos corporais e as respectivas intensidades de desconforto/dor conforme o Diagrama de Corlett e Manenica.

Nota-se na Tabela 2 para a categoria professores, que o lado direito compreendido entre as regiões do pescoço (41), quadril (45) e da mão (24) foram as áreas de maiores reclamações, seguidas das regiões do braço (12) e dorso superior (32) do lado esquerdo. Em estudo de Alves, Araújo e Aguiar (2014) com professores de uma Instituição Pública Municipal de Educação, 71,4\% aponta costas-inferior como o principal problema de dor ou desconforto. Dores nas costas também foram identificadas por Leme e Maia (2015), em estudo com professores de uma Instituição Privada equipada com recursos modernos em sala de aula, como projetor, home theater, notebook e quadro interativo, onde 57,0\% dos entrevistados relataram dor moderada nas costas ao final da jornada de trabalho. Entretanto, a pesquisa dos autores relacionada à dor nos braços, punho ou mão não mostrou ocorrência de desconforto.

Tabela 2. Segmentos corporais e intensidades de desconforto/dor - categoria professores.

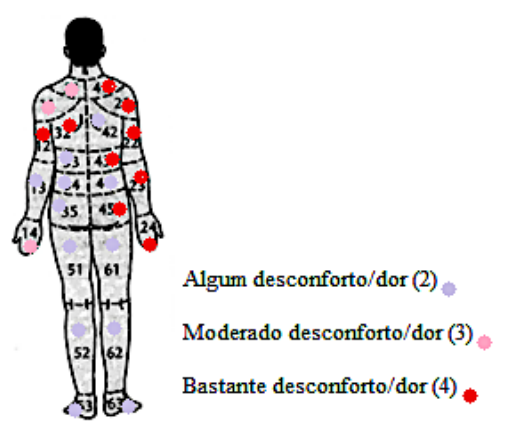

\begin{tabular}{|c|c|c|c|}
\hline Lado esquerdo & $\%$ & Lado direito & $\%$ \\
\hline 11 Ombro & & 21 Ombro & \\
\hline Nenhum desconforto/dor (0) & 8,3 & Moderado desconforto/dor (3) & 2,7 \\
\hline Moderado desconforto/dor (3) & 5,5 & Nenhum desconforto/dor $(0)$ & 5,5 \\
\hline \multirow[t]{3}{*}{ Algum desconforto/dor (2) } & 2,7 & Intolerável desconforto/dor (6) & 2,7 \\
\hline & & Intolerável desconforto/dor (7) & 2,7 \\
\hline & & Algum desconforto/dor (2) & 2,7 \\
\hline 12 Braço & & 22 Braço & \\
\hline Intolerável desconforto/dor (5) & 2,7 & Nenhum desconforto/dor $(0)$ & 8,3 \\
\hline Nenhum desconforto/dor (0) & 11,1 & Intolerável desconforto/dor (6) & 2,7 \\
\hline Moderado desconforto/dor (3) & 2,7 & Algum desconforto/dor (2) & 2,7 \\
\hline 13 Antebraço & & 23 Antebraço & \\
\hline Nenhum desconforto/dor (0) & 11,1 & Nenhum desconforto/dor (0) & 8,3 \\
\hline \multirow[t]{2}{*}{ Algum desconforto/dor (2) } & 2,7 & Intolerável desconforto/dor (6) & 2,7 \\
\hline & & Algum desconforto/dor (2) & 2,7 \\
\hline 14 Mão & & 24 Mão & \\
\hline Nenhum desconforto/dor (0) & 8,3 & Algum desconforto/dor (2) & 5,5 \\
\hline Moderado desconforto/dor (3) & 2,7 & Nenhum desconforto/dor $(0)$ & 5,5 \\
\hline \multirow[t]{2}{*}{ Algum desconforto/dor (2) } & 2,7 & Bastante desconforto/dor (4) & 2,7 \\
\hline & & Moderado desconforto/dor (3) & 2,7 \\
\hline 31 Pescoço & & 41 Pescoço & \\
\hline Nenhum desconforto/dor (0) & 5,5 & Nenhum desconforto/dor (0) & 2,7 \\
\hline Algum desconforto/dor (2) & 2,7 & Intolerável desconforto/dor (6) & 5,5 \\
\hline Moderado desconforto/dor (3) & 2,7 & Algum desconforto/dor (2) & 2,7 \\
\hline Nenhum desconforto/dor (1) & 2,7 & Nenhum desconforto/dor (1) & 2,7 \\
\hline 32 Dorso superior & & 42 Dorso superior & \\
\hline Bastante desconforto/dor (4) & 2,7 & Nenhum desconforto/dor $(0)$ & 11,1 \\
\hline Nenhum desconforto/dor (0) & 11,1 & Algum desconforto/dor (2) & 2,7 \\
\hline Algum desconforto/dor (2) & 2,7 & & \\
\hline 33 Dorso médio & & 43 Dorso médio & \\
\hline Nenhum desconforto/dor $(0)$ & 11,1 & Bastante desconforto/dor (4) & 2,7 \\
\hline \multirow[t]{2}{*}{ Algum desconforto/dor (2) } & 2,7 & Nenhum desconforto/dor $(0)$ & 11,1 \\
\hline & & Algum desconforto/dor (2) & 2,7 \\
\hline 34 Dorso inferior & & 44 Dorso inferior & \\
\hline Nenhum desconforto/dor (0) & 11,1 & Nenhum desconforto/dor $(0)$ & 11,1 \\
\hline
\end{tabular}




\begin{tabular}{|c|c|c|c|}
\hline Algum desconforto/dor (2) & 2,7 & Algum desconforto/dor (2) & 2,7 \\
\hline 35 Quadril & & 45 Quadril & \\
\hline Nenhum desconforto/dor $(0)$ & 8,3 & Nenhum desconforto/dor $(0)$ & 8,3 \\
\hline \multirow[t]{2}{*}{ Algum desconforto/dor (2) } & 5,5 & Bastante desconforto/dor (4) & 2,7 \\
\hline & & Algum desconforto/dor (2) & 2,7 \\
\hline 51 Coxa & & 61 Coxa & \\
\hline Nenhum desconforto/dor $(0)$ & 11,1 & Nenhum desconforto/dor $(0)$ & 11,1 \\
\hline Algum desconforto/dor (2) & 2,7 & Algum desconforto/dor (2) & 2,7 \\
\hline 52 Perna & & 62 Perna & \\
\hline Nenhum desconforto/dor $(0)$ & 11,1 & Nenhum desconforto/dor $(0)$ & 11,1 \\
\hline Algum desconforto/dor (2) & 2,7 & Algum desconforto/dor (2) & 2,7 \\
\hline 53 Pé & & 63 Pé & \\
\hline Nenhum desconforto/dor $(0)$ & 11,1 & Algum desconforto/dor (2) & 5,5 \\
\hline Algum desconforto/dor (2) & 2,7 & Nenhum desconforto/dor $(0)$ & 8,3 \\
\hline
\end{tabular}

Observa-se na Tabela 3 que o ombro (21) do lado direito para 16,6\% da categoria administrativo foi identificado como moderado desconforto/dor (3), assim como o pescoço (41) apresenta algum desconforto/dor (2). As regiões compreendidas entre o pescoço (31) e antebraço (13) lado esquerdo foram consideradas reclamações de dores ou desconfortos ao término da jornada de trabalho. Segundo Safarian, Rahmati-Najarkolaei e Mortezapour (2018) aumentar o conhecimento dos funcionários sobre a condição padrão da estação de trabalho e ajustá-la por conta própria, bem como criar mudanças físicas nas estações de trabalho e substituir alguns equipamentos não ergonômicos pode reduzir o nível de risco e a quantidade de desconfortos musculoesqueléticos em certas áreas do corpo. Ainda, de acordo com os autores, sugere-se que estudos semelhantes devem ser realizados com um projeto combinado de ergonomia, educação e intervenções de organização para reduzir todos os fatores de riscos ergonômicos de escritório (físicos, biomecânicos e psicossociais) e monitorar a administração dessas intervenções por um período de tempo mais longo.

Tabela 3. Segmentos corporais e intensidades de desconforto/dor - categoria administrativo.

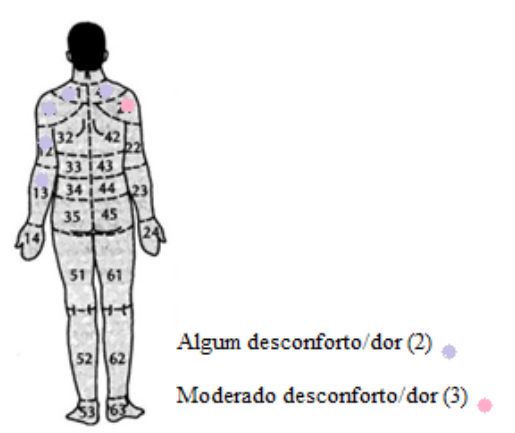

\begin{tabular}{|c|c|c|c|}
\hline Lado esquerdo & $\%$ & Lado direito & $\%$ \\
\hline 11 Ombro & & 21 Ombro & \\
\hline Nenhum desconforto/dor (0) & 16,6 & Moderado desconforto/dor (3) & 16,6 \\
\hline Algum desconforto/dor (2) & 16,6 & & \\
\hline 12 Braço & & 22 Braço & \\
\hline Nenhum desconforto/dor (0) & 16,6 & Nenhum desconforto/dor (1) & 33,3 \\
\hline Algum desconforto/dor (2) & 16,6 & & \\
\hline 13 Antebraço & & 23 Antebraço & \\
\hline Nenhum desconforto & 16,6 & Nenhum desconforto/dor (0) & 16,6 \\
\hline Algum desconforto/dor (2) & 16,6 & & \\
\hline 14 Mão & & 24 Mão & \\
\hline Nenhum desconforto/dor (0) & 16,6 & Nenhum desconforto/dor $(0)$ & 16,6 \\
\hline 31 Pescoço & & 41 Pescoço & \\
\hline Nenhum descon & 16,6 & Algum desconforto/dor (2) & 16,6 \\
\hline Algum desconforto/dor (2) & 16,6 & & \\
\hline 32 Dorso superior & & $42 \mathrm{D}$ & \\
\hline Nenhum desconforto/dor (0) & 16,6 & Nenhum desconforto/dor $(0)$ & 16,6 \\
\hline 33 Dorso médio & & 43 Dorso médio & \\
\hline Nenhum desconforto/dor (0) & 16,6 & Nenhum desconforto/dor (0) & 16,6 \\
\hline 34 Dorso inferior & & 44 Dorso inferior & \\
\hline Nenhum desconforto/dor (0) & 16,6 & Nenhum desconforto/dor (0) & 16,6 \\
\hline
\end{tabular}




\begin{tabular}{lrlc}
35 Quadril & & 45 Quadril & \\
Nenhum desconforto/dor (0) & 16,6 & Nenhum desconforto/dor (0) & 16,6 \\
51 Coxa & & 61 Coxa & \\
Nenhum desconforto/dor (0) & 16,6 & Nenhum desconforto/dor (0) & 16,6 \\
52 Perna & & 62 Perna \\
Nenhum desconforto/dor (0) & 16,6 & Nenhum desconforto/dor (1) & 16,6 \\
53 Pé & & 63 Pé \\
Nenhum desconforto/dor (0) & 16,6 & Nenhum desconforto/dor (0) & 16,6 \\
\hline
\end{tabular}

$\mathrm{Na}$ Tabela 4 para a categoria auxiliar de serviços gerais, observa-se que as regiões do quadril (45) e pé (63) do lado direito foram consideradas de bastante desconforto/dor (4), seguidas de moderado desconforto/dor para as mãos (14-24) e membros inferiores (51-61, 52-62) de ambos os lados. Este fato pode ser explicado em decorrência das posturas adotadas em atividades rotineiras, principalmente nas funções de limpeza de pisos e mobiliários, as quais exigem o encurvamento das regiões lombar e cervical e, levantamento de peso nas atividades de movimentação de mesas, carteiras, cadeiras, entre outros.

Tabela 4. Segmentos corporais e intensidades de desconforto/dor - categoria auxiliar de

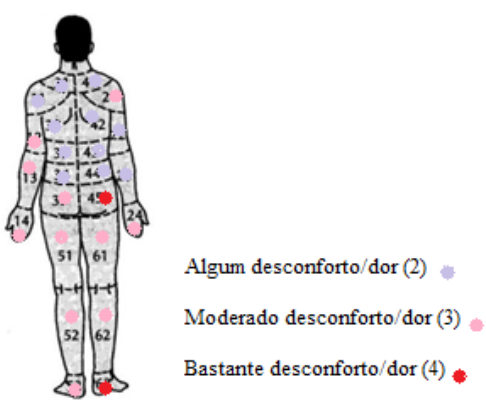

\begin{tabular}{|c|c|c|c|}
\hline Lado esquerdo & $\%$ & Lado direito & $\%$ \\
\hline 11 Ombro & & 21 Ombro & \\
\hline Algum desconforto/dor (2) & 20,0 & Moderado desconforto/dor (3) & 20,0 \\
\hline 12 Braço & & 22 Braço & \\
\hline Moderado desconforto/dor (3) & 20,0 & Algum desconforto/dor (2) & 20,0 \\
\hline 13 Antebraço & & 23 Antebraço & \\
\hline Moderado desconforto/dor (3) & 20,0 & Algum desconforto/dor (2) & 20,0 \\
\hline 14 Mão & & 24 Mão & \\
\hline Moderado desconforto/dor (3) & 20,0 & Moderado desconforto/dor (3) & 20,0 \\
\hline 31 Pescoço & & 41 Pescoço & \\
\hline Algum desconforto/dor (2) & 20,0 & Algum desconforto/dor (2) & 20,0 \\
\hline 32 Dorso superior & & 42 Dorso superior & \\
\hline Algum desconforto/dor (2) & 20,0 & Algum desconforto/dor (2) & 20,0 \\
\hline 33 Dorso médio & & 43 Dorso médio & \\
\hline Algum desconforto/dor (2) & 20,0 & Algum desconforto/dor (2) & 20,0 \\
\hline 34 Dorso inferior & & 44 Dorso inferior & \\
\hline Algum desconforto/dor (2) & 20,0 & Algum desconforto/dor (2) & 20,0 \\
\hline 35 Quadril & & 45 Quadril & \\
\hline Moderado desconforto/dor (3) & 20,0 & Bastante desconforto/dor (4) & 20,0 \\
\hline 51 Coxa & & 61 Coxa & \\
\hline Moderado desconforto/dor (3) & 20,0 & Moderado desconforto/dor (3) & 20,0 \\
\hline 52 Perna & & 62 Perna & \\
\hline Moderado desconforto/dor (3) & 20,0 & Moderado desconforto/dor (3) & 20,0 \\
\hline 53 Pé & & 63 Pé & \\
\hline Moderado desconforto/dor (3) & 20,0 & Bastante desconforto/dor (4) & 20,0 \\
\hline
\end{tabular}

As regiões do dorso (33-44) de ambos os lados foram relatadas como as partes do corpo onde sofrem maior incidência de dores ao final do expediente, decorrentes de tarefas exercidas na função de vigilante, conforme Tabela 5. Trabalho excessivo em pé, além do uso de colete balístico podem estar ligados as dores nessas regiões. 
Tabela 5. Segmentos corporais e intensidades de desconforto/dor - categoria vigilantes.

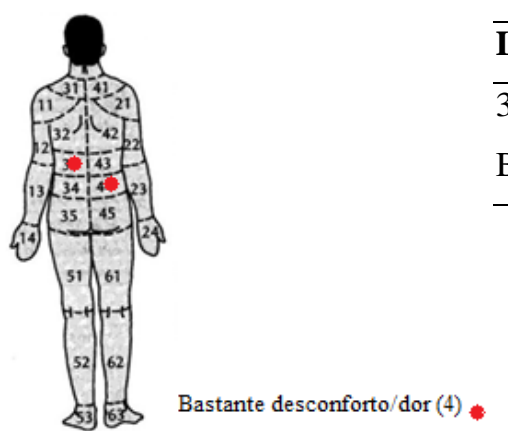

\begin{tabular}{lclc|}
\hline Lado esquerdo & $\%$ & Lado direito & $\%$ \\
\hline 33 Dorso médio & & 44 Dorso inferior & \\
Bastante desconforto/dor (4) & 16,6 & Bastante desconforto/dor (4) & 16,6 \\
\hline
\end{tabular}

Para todas as categorias avaliadas existem queixas relacionadas a desconforto/dor, sendo necessária uma reorganização ergonômica no ambiente educacional (intervenções educacionais e ergonômicas), cita-se o comportamento em posturas, treinamentos em biomecânica, ginástica laboral, pausas/descanso durante a rotina de trabalho, ademais avaliação ergonômica da voz para o grupo professores e treinamentos específicos no uso do EPI para as distintas atividades.

Webinar: Ação Ergonômica - atuais desafios e perspectivas quanto às práticas ergonômicas no ambiente educacional / curso on-line NR 17: o que é e para que serve? - grupo alunos

O número mínimo de alunos foi suficiente para margem de erro de 5\%. Sendo 72 alunos do curso de administração, 93 do curso de automação industrial, 98 do curso de mecânica e 85 do curso de segurança do trabalho.

A Figura 2 retrata o cartaz do evento "AÇÃO ERGONÔMICA" (Figura 2a), que foi divulgado virtualmente nas redes sociais, site da instituição de ensino e grupos de alunos (WhatsApp). Na Figura 2b é mostrada a realização do evento, com a participação dos discentes (público-alvo), de professores e do público externo à comunidade escolar. Professores convidados com expertise na área de docência, saúde e segurança do trabalho conduziram o seminário on-line e o curso sobre NR 17 no contexto acadêmico.

Figura 2. (a) Card e (b) mosaico do Webinar instrucional.

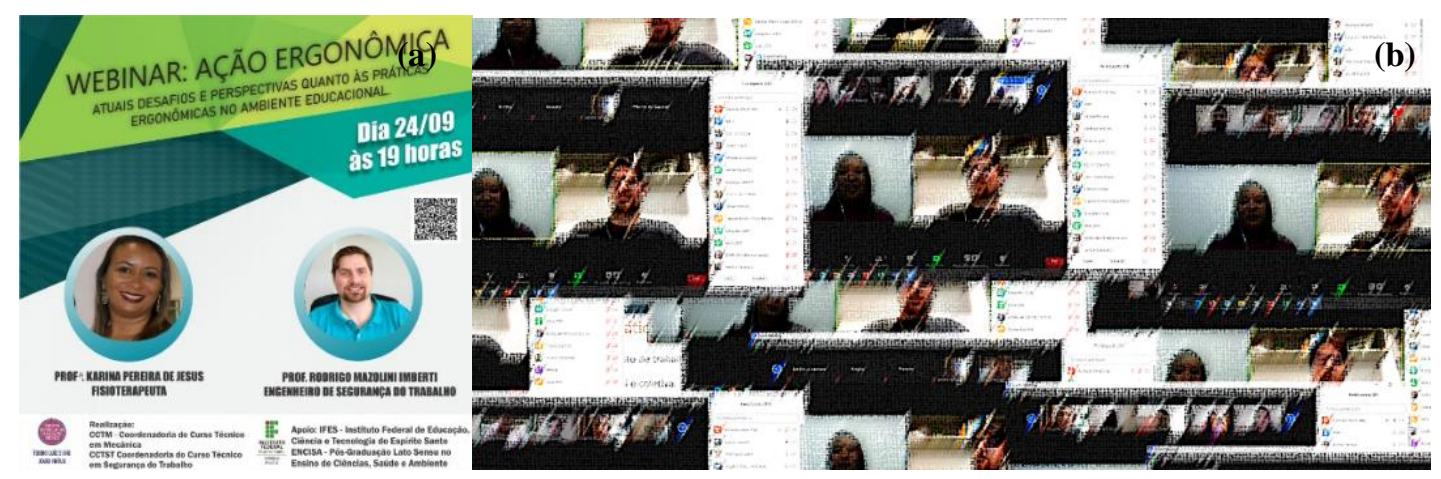

A importância da legislação para a utilização e prática, os requisitos básicos sobre gestão da ergonomia e as melhores práticas de ergonomia para aplicação em atividades acadêmicas e profissionais foram discutidas no curso on-line autoinstrucional "NR 17: O QUE É E PARA QUE SERVE?”, contemplando os tópicos: i. Segurança do trabalho - proteção aos direitos

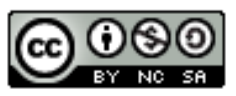


dos trabalhadores; ii. Estruturação da NR 17; iii. Gestão da NR 17 - aspectos práticos; iv. Condições ambientais de trabalho; v. Equipamentos e mobiliários; e vi. Foco na organização do trabalho. Esse evento, assim como a campanha educativa - Webinar são importantes do ponto de vista colaborativo, associativo, discursivo e interativo, de fronteira do prescrito ao real. Outrossim, possibilita uma política de ação ergonômica nas atividades acadêmicas dos alunos de ensino técnico avaliados, podendo ainda ser replicada a outras instituições.

Os alunos participantes dessas intervenções foram compostos por 58,8\% do público feminino e $41,8 \%$ do masculino, compreendidos entre 18 a 25 anos de idade $(61,4 \%)$ e $23,5 \%$ de 26 a 33 anos, distribuídos entre os cursos de segurança do trabalho (54,5\%), mecânica (19,6\%), automação industrial (14,0\%) e administração (11,9\%). Na Tabela 6 são descritas a compreensão dos alunos sobre os direitos dos colaboradores, programas de ergonomia (PE), ergonomia de aprendizagem e instrucional, entre outras.

Tabela 6. Resultados da visão ampla em NR 17.

\begin{tabular}{lcc}
\hline Variáveis avaliadas & \% \\
\hline Conhecimento em... Ergonomia & Sim & 19,0 \\
& Não & 81,0 \\
Conhecimento em... Qualidade no trabalho/aprendizado, saúde, produtividade e segurança & Sim & 22,6 \\
& Não & 77,4 \\
Conhecimento em... Características psicofisiológicas dos trabalhadores & Sim & 33,3 \\
& Não & 66,7 \\
Conhecimento em... Direitos dos trabalhadores & Sim & 11,8 \\
& Não & 88,2 \\
Conhecimento em... Mobiliários, equipamentos mal projetados e a qualidade de vida & Sim & 38,3 \\
& Não & 61,7 \\
Conhecimento em... Programas de ergonomia na instituição de origem & Sim & 7,1 \\
& Não & 92,9 \\
Conhecimento em... Ergonomia de aprendizagem e instrucional aplicadas na instituição de & \\
origem & Sim & 6,5 \\
& Não & 93,5 \\
\hline
\end{tabular}

É possível inferir que existe desconhecimento dos alunos quanto a temática ergonomia e suas áreas abrangentes. Esse resultado representa aspectos negligenciados na educação profissional técnica de nível médio, refletindo no comportamento, concepção e projeto de equipamentos e espaços, bem-estar físico e mental, ademais na macroergonomia. Esse resultado está ligado, em parte, a base de formação do professor, pois segundo Okulova (2020) a ergonomia da educação visa resolver um complexo de tarefas, entre as quais se destacam as tarefas de desenvolvimento da consciência ergonômica individual e social do futuro professor com base na criação de condições de trabalho confortáveis, favoráveis e seguras, tendo em vista os conhecimentos ergonômicos e práticos da atividade ergonômica, atitude responsável ao criar ambiente de aprendizagem conveniente. Além disso, de acordo com Gligorović, Desnica e Palinkaš (2018), alunos iniciantes no curso técnico podem levar

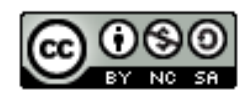


algum tempo até que se sintam confortáveis com seu novo ambiente e se sintam à vontade para expressar opinião sobre o mesmo.

\section{CONCLUSÃo}

Em todas as categorias analisadas (professores, administrativo, ASG, vigilantes), observa-se reclamações de dores pelos participantes do tipo moderadas e intensas ao término da jornada de trabalho, sendo um dos principais fatores de absenteísmo e afastamentos por motivos de saúde desses profissionais da educação.

Houve uma participação expressiva no Webinar e no curso on-line ofertados ao grupo alunos, onde os mesmos permearam pela ergonomia da educação - instrucional e de aprendizagem, com foco no cotidiano acadêmico. A pesquisa mostrou pouco envolvimento neste universo da ergonomia educacional por parte desses discentes de cursos técnicos. Um dos motivos pode estar na formação do docente e na inserção de conteúdos quanto a essa temática, além da interação professor-aluno-ambiente educacional.

O trabalho não apresenta limitações de pesquisa, assim, como perspectiva futura sugere-se a elaboração de um projeto pedagógico institucionalizando a ergonomia na escola, principalmente as instituições profissionalizantes.

\section{Agradecimentos}

Ao Programa de Pós-graduação lato sensu em Ensino de Ciências, Saúde e Ambiente (ENCISA) do Instituto Federal de Educação, Ciência e Tecnologia do Espírito Santo - IFES (Campus Aracruz), ao Centro Estadual de Educação Técnica Talmo Luiz Silva - CEET Talmo Luiz Silva pela estrutura e apoio, assim como os alunos e funcionários, além dos professores Karina Pereira de Jesus e Rodrigo Mazolini Imberti pela parceria no projeto de pesquisa.

\section{REFERÊNCIAS}

ABERGO. Associação Brasileira de Ergonomia. Disponível em: http://www.abergo.org.br/internas.php?pg=o_que_e_ergonomia. Acesso em: 13 maio 2020.

Alves, C. S., Araújo, M. M., \& Aguiar, C. H. A. (2014). Postura ergonômica do profissional docente: Um estudo de caso do Centro de Atenção Integrada à Criança e ao Adolescente (CAIC) Senador Carlos Jereissati, em Russas-CE. Revista Tecnologia \& Informação, 1(3), 20-32. (ISSN 2318 9622)

Alves, W. F. (2018). A invisibilidade do trabalho real: o trabalho docente e as contribuições da ergonomia da atividade. Revista Brasileira de Educação, 23(1), e230089. (http://dx.doi.org/10.1590/S1413-24782018230089)

Ansari, S., Nikpay, A., \& Varmazyar, S. (2018). Design and development of an ergonomic chair for students in educational settings. Health Scope, 7(4), e60531. (https://doi.org/10.5812/jhealthscope.60531)

BRASIL. Lei ${ }^{\circ}$ 10.406, de 10 de janeiro de 2002. Institui o Código Civil. Diário Oficial da União: seção 1, Brasília, DF, ano 139, n. 8, p. 1-74, 11 jan. 2002.

. Ministério do Trabalho. Portaria MTb no 876, de 24 de outubro de 2018 - NR 17. Altera Norma Regulamentadora NR 17 - Ergonomia. Diário Oficial da União: seção 1, Brasília, DF, n. 207, p. 81, 26 out. 2018. 
Cañete, L., Palominos, F., Díaz, H., Córdova, F., \& Cifuentes, F. (2015). Relationship between the ergonomic state of the classroom measured in energy units and the well-being of students observed by non-invasive instrumentation. Procedia Computer Science, 55(1), 28-34. https://doi.org/10.1016/j.procs.2015.07.166

Corlett, E. N., \& Manenica, I. (1980). The effects and measurement of working postures. Applied Ergonomics, 11(1), 7-16. https://doi.org/10.1016/0003-6870(80)90115-5

Fidelis, O. P., Ogunlade, B., Adelakun, S. A., \& Adukwu, O. (2018). Ergonomic analysis of classroom furniture in a Nigerian university. Nigerian Journal of Technology, 37(4), 11541161. https://doi.org/10.4314/njt.v37i4.40

Gligorović, B., Desnica, E., \& Palinkaš, I. (2018). The importance of ergonomics in schools - secondary technical school students' opinion on the comfort of furniture in the classroom for computer aided design. IOP Conf. Series: Materials Science and Engineering, 393(1), 012111. https://doi.org/10.1088/1757-899X/393/1/012111

Guimarães, M. C. (2009). Transformações do trabalho e violência psicológica no serviço público brasileiro. Revista Brasileira de Saúde Ocupacional, 34(120), 163-171. (ISSN 0303 7657).

Leme, A., \& Maia, I. (2015). Evaluation of fatigue at work in teachers using modern resources in the classroom. Procedia Manufacturing, 3(1), 4852-4859. https://doi.org/10.1016/j.promfg.2015.07.601

Okulova, L. P. (2020). An ergonomic approach to higher education of psychology and pedagogy students. Espacios, 41(2), 13-22. (ISSN 0798 1015)

Oyewole, S. A., Haight, J. M., \& Freivalds, A. (2010). The ergonomic design of classroom furniture/computer work station for first graders in the elementary school. International $\begin{array}{llll}\text { Journal of Industrial 437-447. } & \text { Ergonomics, }\end{array}$ https://doi.org/10.1016/j.ergon.2010.02.002

Parvez, M. S., Rahman, A., \& Tasnim, N. (2019). Ergonomic mismatch between students anthropometry and university classroom furniture. Theoretical Issues in Ergonomics Science, 20(5), 603-631. https://doi.org/10.1080/1463922X.2019.1617909

Rantala, L., Sala, E., \& Kankare, E. (2018). Teachers' working postures and their effects on the voice. Folia Phoniatrica et Logopaedica, 70(1), 24-36. https://doi.org/10.1159/000487593

Safarian, M. H., Rahmati-Najarkolaei, F., \& Mortezapour, A. (2018). A comparison of the effects of ergonomic, organization, and education interventions on reducing musculoskeletal $\begin{array}{lllll}\text { disorders in office wealth } & \text { Scope, } & \text { 6(1), } & \text { 6rkers. }\end{array}$ https://doi.org/10.5812/jhealthscope.68422

Sarmento, T. S., Villarouco, V., \& Attaianese, E. (2019). Ergonomic analysis of secondary school classrooms, a qualitative comparison of schools in naples and recife. In: Bagnara, S., Tartaglia, R., Albolino, S., Alexander, T., \& Fujita, Y. (eds) Proceedings of the 20th Congress of the International Ergonomics Association (IEA 2018), 825(1), 537-546. https://doi.org/10.1007/978-3-319-96068-5 60

Silva-Macaia, A. A., Fischer, F. M., Silva, J. P., \& Paparelli, R. Saúde dos professores: uma ambiguidade a resolver. FUNDACENTRO. Atualizado em [09 set. 2016]. Disponível em: http://www.fundacentro.gov.br/dia-10-de-outubro/saude-dos-professores. Acesso em: 13 maio 2020. 